\title{
Nerve Growth Factor (NGF) Augments Cortical and Hippocampal Cholinergic Functioning after p75NGF Receptor-Mediated Deafferentation But Impairs Inhibitory Avoidance and Induces Fear-Related Behaviors
}

\author{
Jürgen Winkler, ${ }^{1,2,3}$ Gilbert A. Ramirez, Leon J. Thal, ${ }^{1,2}$ and Jerene J. Waite ${ }^{1,2}$ \\ 1Department of Neurosciences, University of California San Diego, La Jolla, California 92093-0624, ${ }^{2}$ Neurology Service, \\ Veterans Affairs Medical Center San Diego, San Diego, California 92161, and ${ }^{3}$ Department of Neurology, University of \\ Regensburg, D-93053 Regensburg, Germany
}

Nerve growth factor (NGF) enhances cholinergic functioning in animals with a compromised cholinergic basal forebrain (CBF). Immunotoxic lesions targeting low-affinity NGF receptor (p75NGF receptor)-bearing CBF neurons provide a selective model for testing the effects of NGF on residual cholinergic neurons. Rats received PBS or the immunotoxin 192lgGsaporin (192Sap) intracerebroventricularly at two doses (1 or $2.7 \mu \mathrm{g})$ known to produce different degrees of cholinergic deficit. Seven weeks after lesioning, half of each group received either NGF or cytochrome $c$ intracerebroventricularly for 7 weeks. The two doses of 192Sap produced 50 and $80 \%$ depletions of choline acetyltransferase (ChAT) activity in the neocortex and hippocampus. NGF produced the greatest increase in ChAT activity in controls, intermediate in low-lesioned, and smallest in highly lesioned animals. NGF-treated animals showed reduced weight gain, hyper-responsiveness to acous- tic stimuli, and decreased inhibitory avoidance. Although general motor behavior was affected by neither 192Sap nor NGF in an open field task, highly lesioned rats took longer to reach the platform during water maze testing. Impaired spatial orientation in finding a hidden platform at the previously acquired position was mitigated by NGF. Hypertrophic changes of residual CBF neurons, Schwann cell hyperplasia, and aberrant axonal sprouting around the medulla were observed in NGF-treated animals only, independent of the preexisting lesion. Our results indicate that NGF has a limited capacity to enhance functioning of residual CBF neurons. More importantly, NGF augmented fear-related behaviors and adverse neuroproliferative changes that may restrict its therapeutic use.

Key words: basal forebrain; immunotoxin; 192/gG-saporin; NGF; water maze; inhibitory avoidance; startle response; choline acetyltransferase; low-affinity nerve growth factor receptor
The cholinergic basal forebrain $(\mathrm{CBF})$ has been implicated in cognitive functions including learning, memory, and attention (Kesner, 1988; Fibiger, 1991; Sarter and Bruno, 1997). The cholinergic projections, consisting of the nucleus basalis magnocellularis (NBM) efferents to the neocortex and the amygdala, as well as the medial septum projections to the hippocampus, are affected in Alzheimer's disease (AD) patients (Bartus et al., 1982; Coyle et al., 1983; Collerton, 1986; Emre et al., 1993; Cummings and Kaufer, 1996). Because the cognitive deficits in AD correlate with the extent of CBF degeneration, rodent models with cholinergic deficits are used to test strategies for alleviating cognitive impairments associated with CBF damage (DeKosky et al., 1992; Lehericy et al., 1993).

192IgG-saporin (192Sap) has attracted great attention because it produces dose-dependent, selective lesions of CBF neurons

Received Aug. 12, 1999; revised Oct. 26, 1999; accepted Oct. 29, 1999.

This study was supported by the Research Service of the Veterans Affairs Medical Center, the Sam and Rose Stein Institute for Research on Aging (San Diego, CA), Grant NS33371 from National Institutes of Health, and the Alzheimer's Association-Evelyn T. Stone Memorial Fund Pilot Research Grant. J.W. is National Fellow of the Brookdale Foundation (New York, NY). We thank Dr. E. M. Keithley (Division of Otolaryngology, Head, and Neck Surgery, Department of Surgery, University of California San Diego) for help in measuring the auditory brainstem potentials and comments on this manuscript. We gratefully acknowledge the excellent technical assistance of Andrew Chen and Marilyn L. Wardlow.

Correspondence should be addressed to Dr. Jerene J.Waite, Department of Neurosciences (9151), University of California San Diego, 3350 La Jolla Village Drive, San Diego CA 92161. E-mail: jwaite@ucsd.edu.

Copyright (C) 2000 Society for Neuroscience $0270-6474 / 00 / 200834-11 \$ 15.00 / 0$
(Wiley, 1992; Waite et al., 1994). This immunotoxin is a conjugate of the monoclonal antibody $192 \mathrm{IgG}$ for the low-affinity nerve growth factor receptor (p75NGFr) and the ribosome-inactivating protein saporin (Stirpe et al., 1992). CBF neurons bearing p75NGFr endocytose 192Sap and are permanently destroyed (Wiley et al., 1991). Immunotoxic CBF lesions have produced a substantial loss of cholinergic neurons, a marked and long-lasting decrease of choline acetyltransferase (ChAT) activity, and a variety of cognitive deficits (Wiley et al., 1991; Berger-Sweeney et al., 1994; Waite et al., 1995). However, cholinergic neurons of the NBM projecting to the amygdala do not express p75NGFr and thus are preserved after administration of 192Sap (Heckers and Mesulam, 1994; Heckers et al., 1994).

Nerve growth factor (NGF) is a neurotrophin that enhances cholinergic functioning in the CBF (Hefti, 1994) and prevents lesion-induced behavioral, biochemical, and histological deficits in rodents after cholinergic deafferentation of the hippocampus or the neocortex (Hefti, 1986; Williams et al., 1986; Winkler and Thal, 1995). Additionally, for the cholinergic basal-cortical/amygdala and septal-hippocampal circuits it has been shown that NGF facilitates presynaptic cholinergic neurotransmission in both intact and compromised projections (Lapchak and Hefti, 1991; Rylett et al., 1993).

The capacity of NGF to restore cholinergic hypofunctioning is well established; however, it is unknown how severe a cholinergic deficit can be alleviated by NGF. Although recent data suggest 


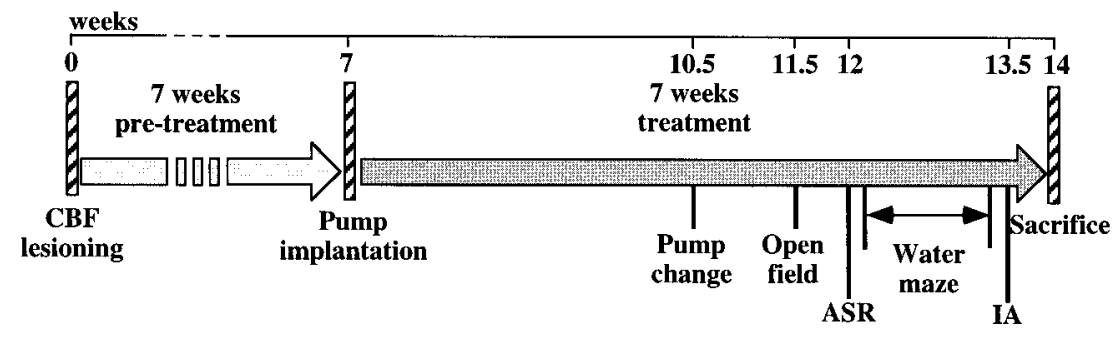

Figure 1. Design of the study. Seven weeks after 192Sap-lesioning (pre-treatment), osmotic minipumps were implanted to continuously administer either NGF or CytC. After changing the pump, all animals were tested consecutively using a behavioral battery consisting of open field, startle response, water maze, and passive avoidance. All animals were decapitated at the end of the 7 weeks of treatment for further biochemical and morphological analysis. that ChAT activity in AD does not decline until relatively late in the course of the disease (Davis et al., 1999), decreases in acetylcholine synthesis occur early and precede the loss of ChAT activity (Francis et al., 1985). The hypothesis of this study is that the ability of NGF to enhance cholinergic functioning depends on the number of residual $\mathrm{CBF}$ neurons and that a therapeutic threshold may exist. It is important to know at which stage trophic factor supplementation to the compromised CBF would still ameliorate deficits. Thus, the goal of this study is to induce different magnitudes of cholinergic defects and to test the efficacy of NGF treatment. A comprehensive characterization using functional tests and biochemical and morphological assessment is used to evaluate the effects of both the lesion and NGF treatment.

\section{MATERIALS AND METHODS}

Subjects. Male Fischer 344 albino rats $(n=44$; Harlan Sprague Dawley, Indianapolis, IN) weighing 260-285 gm (13-14 weeks of age) were maintained in pairs in a large, well lit laboratory controlled for temperature $\left(21^{\circ} \mathrm{C}\right)$ with a daily photoperiod of $12 \mathrm{hr}$ light between 6:00 A.M. and 6:00 P.M. Each animal had free access to water and food and was fed ad libitum on a standard laboratory diet (Teklad 4\% Rat Diet 7001; Harlan Teklad, Madison, WI). Behavioral testing took place during the light cycle. Each of six groups was identified by an abbreviation describing the lesion (low-192Sap or high-192Sap) or controls, which were injected with PBS, and the treatment (NGF) or the control treatment using cytochrome $c(\mathrm{CytC})$. The number of rats in each group is given in parentheses: PBS/NGF (8), PBS/CytC (7), low-192Sap/NGF (9), low192Sap/CytC (8), high-192Sap/NGF (6), and high-192Sap/CytC (6). The behavioral testing took place between the fourth and seventh weeks of treatment, corresponding to the 11th and 14th weeks after lesioning. The temporal design of the present study is summarized in Figure 1.

Surgery. Rats were anesthetized by an intramuscular injection consisting of $62.5 \mathrm{mg} / \mathrm{kg}$ ketamine (Ketaset, $100 \mathrm{mg} / \mathrm{ml}$; Bristol Laboratories, Syracuse, NY), 3.175 mg/kg xylazine (Rompun, 20 mg/ml; Miles Laboratories, Shawnee, $\mathrm{KS}$ ), and $0.625 \mathrm{mg} / \mathrm{kg}$ acepromazine maleate (10 $\mathrm{mg} / \mathrm{ml}$; TechAmerica Group Inc., Elwood, KS) diluted in $0.9 \%$ sterile saline. 192Sap was obtained as a gift from Dr. R. G. Wiley (Veterans Affairs Medical Center and Departments of Neurology and Pharmacology, Vanderbilt University, Nashville, TN) and Dr. D. A. Lappi (Advanced Targeting Systems, San Diego, CA) and prepared from a stock solution of 192Sap at an initial concentration of $0.666 \mu \mathrm{g} / \mu \mathrm{l}$. 192Sap was infused intracerebroventricularly at anteroposterior (AP), $8.0 \mathrm{~mm}$; lateral, $1.5 \mathrm{~mm}$; and dorsoventral, $5.8 \mathrm{~mm}$ (coordinates according to the atlas of Paxinos and Watson, 1986) from the center point of the interaural line with the animal mounted in the flat skull position on a Kopf stereotaxic instrument. Two dosages (1.0 and 2.7 $\mu \mathrm{g}$ ) of 192Sap in a total volume of $10 \mu \mathrm{l}$ of PBS were administered freehand over 10 sec using a blunt-tipped, 26-gauge, $10 \mu \mathrm{l}$ Hamilton syringe. Five minutes of diff usion time were allowed before the needle was retracted. The control group received PBS infusions. Seven weeks after lesioning, osmotic minipumps (2002; Alza, Palo Alto, CA) were implanted subcutaneously and connected to a stainless steel cannula implanted in the lateral ventricle as previously described (Winkler and Thal, 1995). The pumps contained either human recombinant NGF (884 $\mathrm{g} / \mathrm{ml}$; Syntex Corp., Palo Alto, $\mathrm{CA})$ or rat CytC $(884 \mu \mathrm{g} / \mathrm{ml}$; Sigma, St. Louis, MO) in artificial CSF containing $100 \mu \mathrm{g} / \mathrm{ml}$ rat serum albumin (Sigma) and $50 \mu \mathrm{g} / \mathrm{ml}$ gentamycin (Sigma). The pumps had a flow rate of $0.25 \mu \mathrm{l} / \mathrm{hr}$ delivering either NGF or CytC at $5 \mu \mathrm{g} / \mathrm{d}$ per rat. The animals were continuously treated for 7 weeks, necessitating a pump change after 3.5 weeks (Fig. 1).
Measurement of animal body weight. All animals were weighed at weekly intervals throughout the duration of the experiment, beginning at the day of lesioning. The groups (PBS, low-192Sap, and high-192Sap) were divided in half so that the groups had similar mean weights at the start of the treatment phase.

Behavioral assessment (open field, acoustic startle response, water maze, inhibitory avoidance, and auditory brainstem response). Behavioral tests were initiated 11.5 weeks after lesioning. At this time, the animals had been continuously inf used with NGF for 4.5 weeks (Fig. 1). Six days after pump change, open field activity was measured by counting the number of grid lines crossed by both hind feet for periods of $1 \mathrm{~min}$ and $5 \mathrm{~min}$ in a $81 \times 81 \mathrm{~cm}^{2}$ box marked with a grid of $20 \mathrm{~cm}$ squares.

One day later, acoustic startle response (ASR) was tested by measuring the maximal motor response to a $115 \mathrm{~dB}$ stimulus ( $50 \mathrm{msec}$ duration) for 56 trials spaced an average of $15 \mathrm{sec}$ apart (range, 12-18 sec) (Waite et al., 1995). The displacement of the rats was measured for $200 \mathrm{msec}$ beginning at the onset of the stimulus. Seven of the 56 trials were null trials during which displacement was recorded in the absence of an acoustic stimulus. A $60 \mathrm{~dB}$ background of white noise was constant throughout the testing and during the $5 \mathrm{~min}$ acclimation period before testing began. Maximum displacements, measured by the piezoelectric accelerometer, were recorded in arbitrary units by the computer-run system (SR Lab; San Diego Instruments, San Diego, CA).

Acquisition and retention of spatial navigation were measured in the water maze. The position of the white rat in the black, circular fiberglass pool (diameter, $152 \mathrm{~cm}$ ) was automatically recorded by means of a video camera and a video tracking device with Chromotrack software (San Diego Instruments). For the purpose of data description, the pool was divided into four quadrants and three annuli as previously described (Dekker et al., 1992). The platform had a constant location in the center of quadrant 3 between the outer and the inner edges of annulus 2 . The area defined by the intersection of the platform quadrant (PQ) and platform annulus (PA) was defined as the target area (TA). To test vision and the ability to swim and climb, each rat was trained during three two-trial (each $90 \mathrm{sec}$ ) blocks to escape from the water $\left(19-21^{\circ} \mathrm{C}\right)$ to a $10 \times 10 \mathrm{~cm}^{2}$ black platform, which was submerged $3 \mathrm{~cm}$ under the water surface. The platform was marked with two wooden sticks (diameter, 0.5 $\mathrm{cm}$ ) extending $7 \mathrm{~cm}$ above the water surface, providing each rat with intramaze cues. The sticks were placed on opposite corners of the platform, allowing the rat to sit between them. One block consisted of two trials, the first starting from a location farthest from the platform, the second from one of the closer locations. Release points were chosen semirandomly, and the trial ended if the rat remained on the platform 3 sec. In addition, the rat was required to sit on the platform for $10 \mathrm{sec}$. The intertrial and interblock intervals were $15 \mathrm{sec}$. The following day, the same protocol was followed, except the platform was unmarked and invisible from the water surface. Ten days after the acquisition, retention was measured using one two-trial (each $90 \mathrm{sec}$ ) block. The next day, spatial accuracy was measured in one $90 \mathrm{sec}$ trial without the platform. Distance spent in PQ, TA, and the swimming speed were measured in the fixed 90 sec spatial probe trial.

Single-trial, step-through, inhibitory avoidance (IA) was tested using a two-compartment box. Each animal was placed in the lighted compartment for $15 \mathrm{sec}$ before a guillotine door to the dark compartment was raised, and a timer began to record step-through latency. Passage into the dark was considered complete when all four paws had entered the chamber. The door was closed, and a $0.65 \mathrm{~mA}$ AC scrambled current was applied for $5 \mathrm{sec}$ to the metal bars comprising the floor of the chamber. The rat remained in the dark for $15 \mathrm{sec}$ and was then placed in its home cage. Inhibitory avoidance retention (IAR) after $72 \mathrm{hr}$ was assessed as the step-through latency described above. No shock was delivered in the 
Table 1. ChAT activities of all regions after 7 weeks of CytC or NGF treatment

\begin{tabular}{|c|c|c|c|c|c|c|c|}
\hline Group & Frontal & Parietal & Occipital & Cingulate & Hippocampus & Olfactory bulbs & $\begin{array}{l}\% \text { across all } \\
\text { regions }\end{array}$ \\
\hline PBS/CytC & $44.3 \pm 1.2(100)$ & $35.5 \pm 1.2(100)$ & $42.5 \pm 1.2(100)$ & $50.6 \pm 2.3(100)$ & $46.0 \pm 1.3(100)$ & $26.3 \pm 0.8(100)$ & $100 \pm 1.4$ \\
\hline $\mathrm{PBS} / \mathrm{NGF}$ & $69.5 \pm 3.4(157)^{*}$ & $44.1 \pm 1.8(124)^{*}$ & $64.3 \pm 4.0(151)^{*}$ & $75.0 \pm 5.6(148)^{*}$ & $58.0 \pm 1.5(126)^{*}$ & $37.9 \pm 1.9(144)^{*}$ & $141.6 \pm 6.3^{*}$ \\
\hline Low-192Sap/CytC & $30.2 \pm 2.4(68)^{* * *}$ & $17.3 \pm 2.3(49)^{* *}$ & $12.6 \pm 1.1(30)^{* * *}$ & $17.9 \pm 3.1(35)^{* *}$ & $25.1 \pm 3.4(55)^{* *}$ & $15.1 \pm 0.7(57)^{* *}$ & $49.0 \pm 4.5^{* *}$ \\
\hline Low-192Sap/NGF & $46.7 \pm 4.2(105)^{*}$ & $23.3 \pm 3.1(66)^{* * *}$ & $13.7 \pm 2.0(32)$ & $22.9 \pm 7.3(45)$ & $30.3 \pm 6.1(66)$ & $22.2 \pm 4.2(86)^{*}$ & $66.4 \pm 10.0^{*}$ \\
\hline High-192Sap/CytC & $15.5 \pm 3.1(35)^{* * *}$ & $8.8 \pm 3.0(25)^{* *}$ & $7.5 \pm 1.1(18)^{* *}$ & $7.6 \pm 1.9(15)^{* *}$ & $7.1 \pm 3.4(15)^{* *}$ & $2.3 \pm 0.9(9)^{* *}$ & $19.3 \pm 5.4^{* *}$ \\
\hline High-192Sap/NGF & $21.8 \pm 3.0(49)$ & $8.7 \pm 1.8(24)$ & $7.7 \pm 0.6(18)$ & $6.5 \pm 0.3(13)$ & $10.7 \pm 2.8(23)$ & $4.2 \pm 1.6(16)$ & $23.9 \pm 3.6$ \\
\hline
\end{tabular}

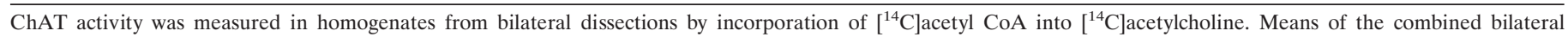

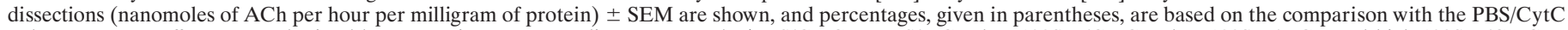

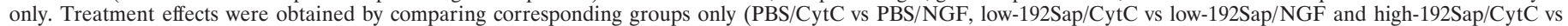

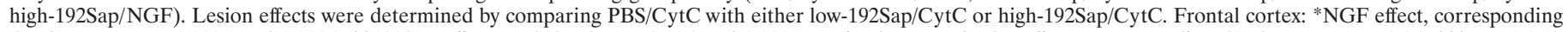

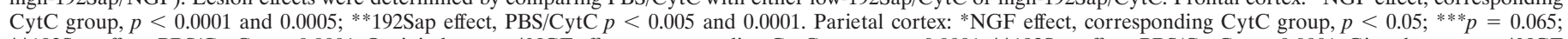

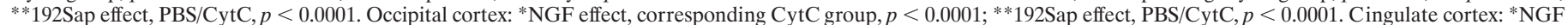

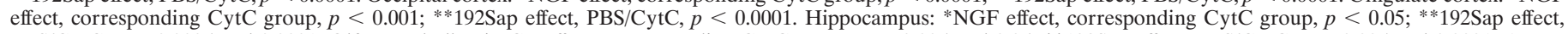

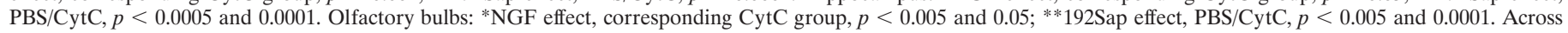
all regions: *NGF effect, corresponding CytC group, $p<0.0001$ and 0.05 ; **192Sap effect, PBS/CytC, $p<0.0001$.

single retention trial. A maximum time of $600 \mathrm{sec}$ was allowed before a rat was removed from the lighted compartment.

Auditory brainstem response. The threshold for the auditory brainstem response (ABR) reflecting the peripheral and partially the central afferent pathway of the eighth (vestibulocochlear) cranial nerve was determined in a representative subset of animals (Keithley et al., 1989). The selected animals ( $n=2$ per each group) had ASRs that were similar to the corresponding ASR means of each group. The rats were anesthetized as described for surgeries and were examined otoscopically before testing. The animals were then placed in the dark, sound-attenuated chamber, which was electrically shielded and grounded. A heating pad maintained a stable body temperature. Platinum electrodes were placed in the vertex (active), in the retroauricular region (reference), and in the right hindlimb (ground). Auditory function was assessed by obtaining ABR thresholds from both ears of each rat. The acoustic stimuli were produced by a Grass S-88 stimulator and delivered to the ear through an earphone in a closed system. The clicks were presented at a repetition rate of $10 \mathrm{~Hz}$ with a stimulus duration of $0.1 \mathrm{msec}$ and were attenuated with a HewlettPackard $350 \mathrm{D}$ attenuator. The output of the electrodes was preamplified (1000 times) by an EG\&G Parc 113 amplifier, filtered $(0.1-3 \mathrm{KHz})$, and averaged with a Hewlett-Packard 3561A dynamic signal analyzer for 512 stimulus presentations. Thresholds were determined by obtaining an $\mathrm{ABR}$ in response to a loud click and subsequently by attenuating the stimulus until the response could not be obtained. The threshold was defined as the midpoint of stimulus loudness that evoked an ABR and did not evoke a response. After averaging, each averaged ABR was plotted with a Hewlett-Packard 7550A graphics plotter.

ChAT activity. The animals were decapitated at the end of the behavioral testing, corresponding to 14 weeks after lesioning and 7 weeks of NGF treatment, respectively. The brains were rapidly removed and dissected on ice. Two portions of the brain, a $3 \mathrm{~mm}$ slice ( $\sim 6.5-9.5 \mathrm{AP})$ of the forebrain and the entire hindbrain, were saved for histology. The frontal, parietal, posterior cingulate and occipital neocortex, hippocampus, and olfactory bulbs were dissected and sonicated in $400 \mu \mathrm{l}$ of $50 \mathrm{~mm}$ phosphate buffer, $\mathrm{pH}$ 7.4. ChAT activity was measured by the incorporation of $\left[{ }^{14} \mathrm{C}\right]$ acetyl-coenzyme $\mathrm{A}$ into $\left[{ }^{14} \mathrm{C}\right] \mathrm{ACh}$ (Fonnum, 1969). The protein content of the samples was determined by the method of Lowry et al. (1951).

Monoamines and their metabolites. Protein in the sonicated homogenates from the left and right brain regions was precipitated by addition of a 1/20 volume of $2 \mathrm{M}$ ice-cold perchloric acid containing $16 \mathrm{~mm}$ sodium metabisulfite and $0.04 \mathrm{~mm}$ disodium EDTA. After a 10 min centrifugation $\left(12,000 \times g, 4^{\circ} \mathrm{C}\right)$, clear supernatants were removed and stored at $-80^{\circ} \mathrm{C}$ for later analysis of monoamines and their metabolite content. An aliquot $(40 \mu \mathrm{l})$ of the clear perchloric acid extract was analyzed for the presence of epinephrine (EPI), norepinephrine (NE), dopamine (DA), serotonin (5-HT), 3,4-dihydroxyphenylacetic acid (DOPAC), homovanillic acid (HVA), 5-hydroxyindoleacetic acid (5-HIAA), 3-methoxy-4-hydroxyphenylglycol (MHPG), and 3-methoxytyramine (3MT) by HPLC as previously described (Winkler et al., 1998). Four groups (PBS/CytC, PBS/NGF, high-192Sap/CytC, and high-192Sap/ NGF) were chosen for assay based on the large magnitude of ChAT changes of these groups.
Histology. The $3 \mathrm{~mm}$ slice of the forebrain and the hindbrain including pons, medulla oblongata, and cerebellum were fixed in $10 \%$ formalin for $2 \mathrm{~d}$ and stored in $0.32 \mathrm{~m}$ sucrose at $4^{\circ} \mathrm{C}$. Forty-micrometer-thick sections were cut on a sliding microtome and stored in a cryoprotectant solution (glycerol, ethyleneglycol, and 0.1 M phosphate buffer, $\mathrm{pH} 7.4,3: 3: 4 \mathrm{v} / \mathrm{v} / \mathrm{v}$ ). Sections were stained with cresyl violet. Every sixth section of the forebrain was immunostained for p75NGFr (Winkler et al., 1998). Briefly, endogenous peroxidase enzyme activity was blocked with $0.6 \%$ $\mathrm{H}_{2} \mathrm{O}_{2}$ for $30 \mathrm{~min}$, after which sections were rinsed with $1 \%$ horse serum and $0.25 \%$ Triton X-100 in $0.1 \mathrm{M}$ Tris-buffered saline, $\mathrm{pH}$ 7.4. Subsequently, sections were incubated overnight with a monoclonal antibody against p75NGFr (1 mg/125 ml; $192 \mathrm{IgG}$, from mouse hybridoma; obtained as gift from Dr. F. H. Gage, Salk Institute, La Jolla, CA), rinsed twice for $10 \mathrm{~min}$ with Tris-buffered saline, incubated for $1 \mathrm{hr}$ with the secondary antibody (horse anti-mouse, biotinylated, 1:160 dilution; Vector Laboratories, Burlingame, CA), rinsed twice for 10 min with Trisbuffered saline, and incubated for $1 \mathrm{hr}$ with avidin and biotinylated peroxidase (1:100; Vector). Staining was visualized with a 5 min incubation in $0.025 \%$ diaminobenzidine, $0.01 \% \mathrm{H}_{2} \mathrm{O}_{2}$, and $0.6 \%$ nickel chloride in Tris-buffered saline.

Statistical analysis. The study was designed to evaluate NGF effects by comparing corresponding treatment groups such as $\mathrm{PBS} / \mathrm{CytC}$ versus PBS/NGF, low-192Sap/CytC versus low-192Sap/NGF, and high-192Sap/ CytC versus high-192Sap/NGF. Lesion effects were determined by comparing PBS/CytC with either low-192Sap/CytC or high-192Sap/CytC.

Differences among groups were evaluated by ANOVA. Repeated measures ANOVA was used for the analysis of weight changes, startle response, and water maze acquisition. ChAT activity was analyzed across all groups and regions by a two-way ANOVA (group $\times$ brain region) followed by Fisher's protected least significant difference (LSD) post hoc test. Because IA performance on training and retention did not assume a normal distribution, these data were analyzed using a KruskalWallis test, followed by a Mann-Whitney $U$ test. Significance criterion was set at $p \leq 0.05$. Levels of monoamines and their metabolites were analyzed across all groups by a series of two-way ANOVAs (brain region $\times$ group). Significance criterion for these ANOVAs was modified in accordance with the Bonferroni method followed by Fisher's protected LSD post hoc test if the result was significant (Dixon and Massey, 1983).

\section{RESULTS}

To understand the functional consequences produced by NGF and 192Sap, it is useful to present the biochemical and morphological results first.

\section{Sap induces a graded, p75NGFr-mediated cholinergic deafferentation}

We examined the regional brain ChAT activity (Table 1). There was a significant group effect in all regions $(p<0.0001)$. The immunotoxin-lesioned animals showed an overall dosedependent decrease in ChAT activity. The lower dosage of 192Sap $(1.0 \mu \mathrm{g})$ caused a mean depletion of $\sim 51 \%$ (range be- 


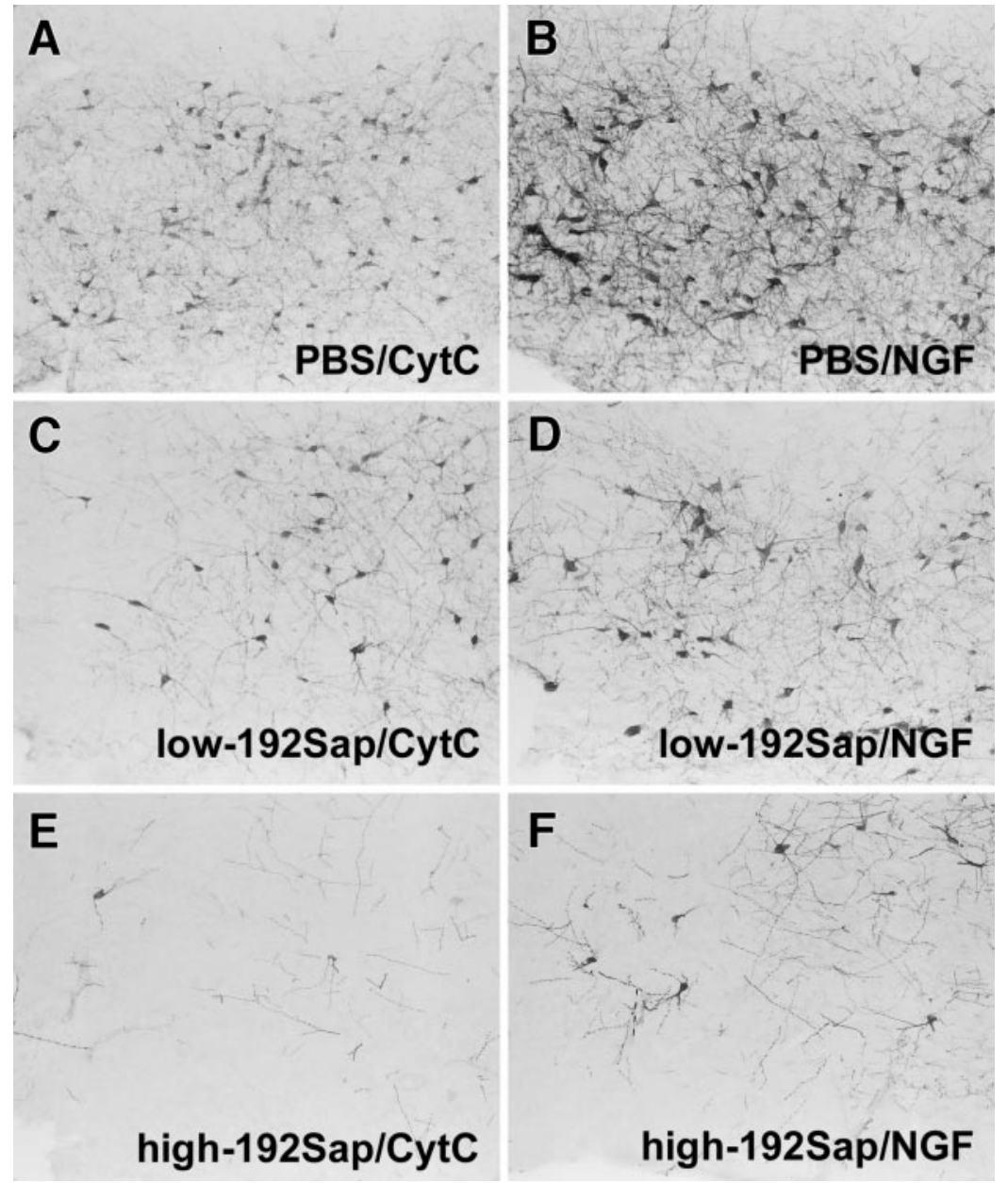

Figure 2. Loss of p75NGFr-immunoreactive CBF neurons after immunotoxic lesioning accompanied by NGF-induced hypertrophic changes. Representative photomicrographs of the anterior part of the NBM show the different degrees of diminished p75NGFr-immunoreactive neurons after injection of PBS $(A), 1 \mu \mathrm{g}$ of 192Sap $(C)$, and $2.7 \mu \mathrm{g}$ 192Sap $(E)$. The area of p75NGFr-immunoreactive neurons as well as the density of neuritic sprouting are increased in the PBS/NGF animals $(B)$ but also in the immunotoxic lesioned animals independent of the remaining number of p75NGFrimmunoreactive neurons $(D, F)$. tween $32 \%$ depletion in the frontal cortex and $70 \%$ depletion in the occipital cortex), whereas the higher dosage of 192Sap (2.7 $\mu \mathrm{g}$ ) reached an average depletion of $81 \%$ (range between $65 \%$ depletion in the frontal cortex and $91 \%$ depletion in the olfactory bulbs). The degree of immunotoxin-induced ChAT depletion was comparable with previous reports using similar doses of 192Sap (Waite et al., 1994; Walsh et al., 1995). The dose-dependent extent of neocortical ChAT depletions varied among the different regions for both dosages $(1.0$ and $2.7 \mu \mathrm{g})$. In particular, the occipital and cingulate cortices were much more affected by the two dosages of the immunotoxin than the frontal and parietal cortices.

\section{NGF restores ChAT in 50\% p75NGFr-mediated deafferentation, but not $80 \%$}

There was a significant NGF effect across all regions and in each region separately in $\mathrm{PBS} / \mathrm{NGF}$ animals, ranging from $24 \%$ increase of ChAT activity in the parietal cortex to $57 \%$ increase in the frontal cortex (Table 1). These data confirm previous findings that the $\mathrm{CBF}$ is not saturated by endogenous NGF levels, because cholinergic markers in unlesioned animals can be further elevated by additional trophic factor supplementation (Fusco et al., 1989; Winkler and Thal, 1995; Winkler et al., 1998). The low-192Sap/ NGF group was significantly different from the corresponding low-192Sap/CytC in the group-by-all-regions analysis $(p \leq 0.05$; Table 1). For individual regions, frontal ChAT activity of low192Sap-lesioned animals was fully restored by NGF up to the level of PBS controls and was significantly elevated compared with low-192Sap/CytC animals $(p<0.0005)$. In addition, NGF partially restored ChAT activity in the olfactory bulb by $29 \%$ $(p<0.05)$ and the parietal cortex by $17 \%$ (nonsignificant, $p=$ 0.065 ) of the low-192Sap-lesioned group. Overall, NGF failed to increase ChAT activity after high-dose 192Sap lesioning. For example, NGF induced a nonsignificant increase of $6 \%$ in frontal ChAT activity. These results indicate that NGF had the capacity to partially restore ChAT activity in animals with a mean depletion of $51 \%$ but could not restore ChAT activity significantly in animals with a preexisting mean depletion of $81 \%$.

\section{NGF and 192Sap do not affect noncholinergic neurotransmitter levels}

The tissue content of the monoamines and their metabolites (EPI, NE, HVA, DA, DOPA, DOPAC, 5-HT, 5-HIAA, MHPG, and 3-MT) was not significantly different between corresponding groups in all regions (all $p>0.005$ according to Bonferroni; data not shown). Neither immunotoxic lesioning nor treatment with NGF altered noradrenergic, dopaminergic, or serotonergic neurotransmitter levels or their metabolites in any CBF projection analyzed.

\section{NGF induces hypertrophic changes of residual CBF neurons and Schwann cell hyperplasia around the medulla independent of the preexisting cholinergic lesion}

As shown previously (Waite et al., 1995; Walsh et al., 1995), the number of p75NGFr-immunoreactive neurons localized in the 
Figure 3. NGF-induced Schwann cell hyperplasia and neuritic sprouting. Representantive photomicrographs of cresyl violet staining of the lower medulla at the level of the hypoglossal nuclei showing the hyperplasia $(H)$ of the Schwann cells beneath the pial cells, the trigeminal tract $(T T)$, and trigeminal nuclei $(T N)$. Note some Schwann cells are present along a vessel perpendicular to the surface of the medulla. $A$, Low-192Sap/CytC; $B$, low-192Sap/NGF. All NGF-treated animals, regardless of whether they were lesioned, showed a similar extent of Schwann cell hyperplasia.
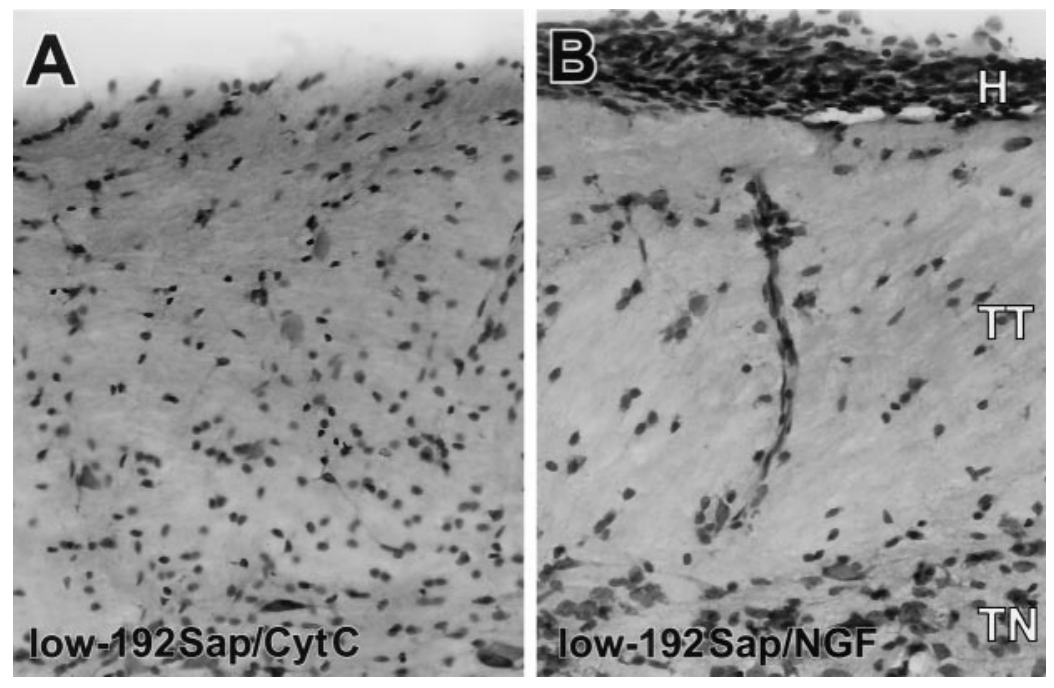

NBM, diagonal band of Broca, and medial septum was dramatically reduced in low- and high-192Sap lesioned groups compared with the PBS controls (Fig. 2). In addition, in representative sections of low- and high-192Sap lesioned animals, the loss of p75NGFr-immunoreactive CBF neurons was much greater in animals with high-192Sap lesions compared with animals with low-192Sap lesions (Fig. 2). NGF induced hypertrophy and sprouting of neurites of the residual cholinergic neurons. PBS/ NGF animals showed hypertrophic p75NGFr-immunoreactive neurons within the entire $\mathrm{CBF}$ associated with an enhanced network of p75NGFr-immunoreactive neurites compared with CytC controls. In addition, treatment with NGF resulted in similar changes in the low- and high-192Sap lesioned animals.

The medulla of NGF-treated animals was surrounded by a substantial hyperplasia of Schwann cells. The hyperplastic changes were limited to the caudal portion of the medulla starting at the level of the 11th and 12th cranial nerves without extending to more rostral structures of the hindbrain or forebrain. This neuroproliferative effect of NGF has been observed in rodents and primates at doses ranging from 6 to $60,000 \mathrm{ng} / \mathrm{d}$ and is independent of rat strain or sex (Day-Lollini et al., 1997; Winkler et al., 1997). The Schwann cells were predominantly attached to the dorsolateral surface of the medulla in close anatomical proximity to the trigeminal tract and arteries (Fig. 3). This NGFinduced Schwann cell hyperplasia was independent of the preexisting cholinergic deficit and was observed to a similar degree in PBS, low- and high-192Sap lesioned animals. Sensory and sympathetic fibers were abundantly and closely associated with the NGF-induced Schwann cell hyperplasia.

The higher dosage of 192Sap $(2.7 \mu \mathrm{g})$ resulted in Purkinje cell loss in the superficial layers of the cerebellum, whereas PBS and the lower dosage of 192Sap $(1.0 \mu \mathrm{g})$ had no effect on these cells. NGF had no effect on the cell number and size of Purkinje cells (data not shown).

\section{NGF reduces body weight gain independent of the preexisting cholinergic lesion}

During the pretreatment period all animals significantly gained weight between lesioning and the start of treatment $\left(F_{(2,41)}=\right.$ $479.89 ; p<0.05)$. The course of weight gain did not differ between the controls and the immunotoxin lesioned animals (group-by-time interaction, $F_{(2,41)}=1.66$ ). No significant group difference was found in average body weights among groups $\left(F_{(2,41)}=0.68\right)$.

Confirming previous findings (Williams, 1991; Winkler and Thal, 1995; Winkler et al., 1998), treatment with NGF significantly affected both the average body weight $\left(F_{(5,38)}=14.89 ; p<\right.$ 0.0001 ) and the course of weight gain between groups (time-bygroup interaction, $\left.F_{(20,152)}=15.06 ; p<0.0001\right)$. However, hypophagia is observed after intracerebroventricular administration of various growth factors such as brain-derived neurotrophic factor, fibroblast growth factor, and ciliary neurotrophic factor (Lapchak and Hefti, 1992; Henderson et al., 1994; Emmett et al., 1995), indicating a rather nonspecific effect of growth factors on structures that abut the ventricular system. In agreement with these findings, NGF-treated animals had a significantly lower body weight, independent of the extent of lesioning (Fig. 4a). Throughout the entire treatment period, there was a significant difference in the average body weight among groups (week $2, F_{(5,38)}=11.96$; $p<0.0001$; week $3.5, F_{(5,38)}=15.75 ; p<0.0001$; week $5, F_{(5,38)}$ $=26.97 ; p<0.0001$; week $\left.7, F_{(5,38)}=15.44, p<0.0001\right)$. For example, during the treatment period, the CytC-groups gained between 38 and $43 \mathrm{gm}$, whereas the NGF-treated animals lost between 3 and $27 \mathrm{gm}$ (Fig. $4 b$ ).

\section{NGF and 192Sap do not affect general motor behavior}

Initial spontaneous motor activity was assessed by counting grid lines crossed by the rat in a walled square box for a $1 \mathrm{~min}$ (Table $2)$. There was no difference among groups $\left(F_{(5,38)}=0.50\right)$. In addition, neither immunotoxic lesioning nor NGF treatment significantly altered exploratory spontaneous motor behavior during the entire 5 min duration of this task $\left(F_{(5,38)}=0.91\right.$; Table 2$)$.

\section{NGF induces hyper-responsiveness to acoustic stimuli independent of the preexisting cholinergic lesion}

Motor reactivity and habituation to a $115 \mathrm{~dB}$ acoustic stimulus were tested. Data were analyzed in eight blocks of six consecutive trials, excluding the first trial for each rat and all null trials. Highly significant group (repeated measures ANOVA, $F_{(5,38)}=8.1 ; p<$ $0.0001)$ and block effects $\left(F_{(7,266)}=3.5 ; p<0.001\right)$ but no group-by-block interaction was found $\left(F_{(35,266)}=0.7 ; p>0.05\right)$. Total reactivity summed across the eight blocks was significantly increased by the NGF treatment regardless of whether the animals were lesioned (Fig. 5a). In contrast, habituation was not 
a.

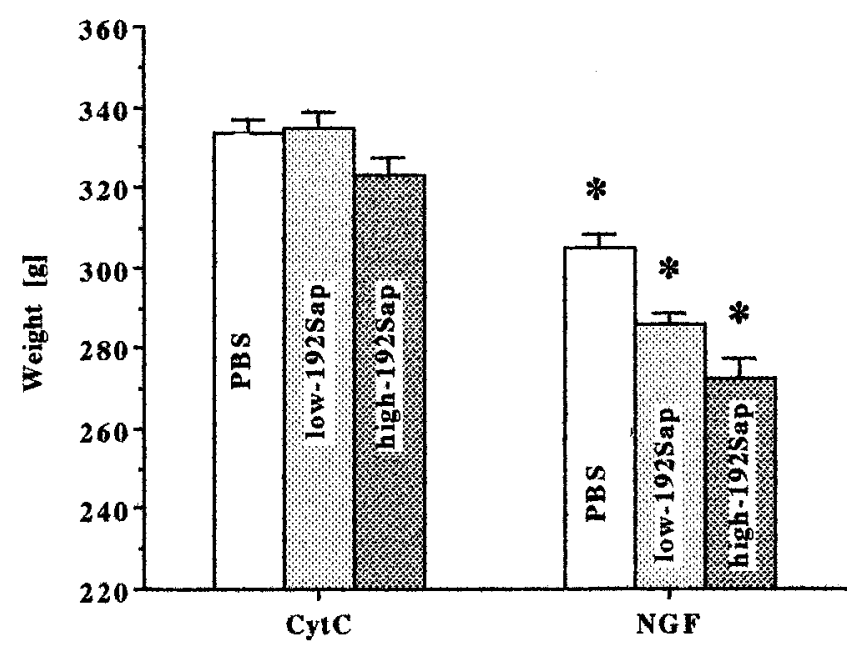

b.

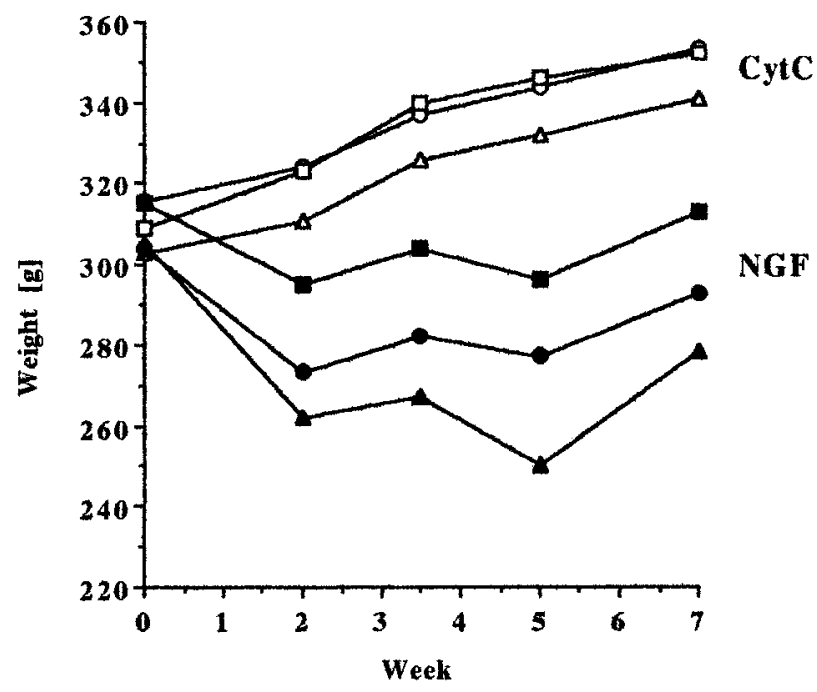

Figure 4. a, Animal weight-NGF reduces mean body mass. NGF significantly affected the average body weight $\left(F_{(5,38)}=14.89 ; p<0.0001\right)$. NGF-treated animals had a significantly lower mean body mass, independent of the extent of lesioning. Animals were weighed weekly until the end of treatment. Data are expressed as means \pm SEM. *Significant difference from the corresponding CytC group; PBS, $p<0.005$; low192Sap, $p<0.0001$; high-192Sap, $p<0.0001$. $b$, Animal weight-NGF decreases weight gain. Animals were continuously treated with NGF or $\mathrm{CytC}$ via intracerebroventricular cannulas. Body weights were measured week 0 (pump implantation), week 2, week 3.5 (pump change), week 5 , and week 7 (end of treatment). NGF significantly altered weight gain throughout the treatment period (time-by-group interaction, $F_{(20,152)}=$ 15.06; $p<0.0001$ ). In particular, NGF-treated animals never gained body mass similar to the corresponding $\mathrm{CytC}$ controls. Each point represents the average body weight of the group during the treatment period. Open squares, PBS/CytC; closed squares, PBS/NGF; open circles, low-192Sap/ CytC; closed circles, low-192Sap/NGF; open triangles, high-192Sap/CytC; closed triangles, high-192Sap/NGF.

altered by either the immunotoxic lesioning or the NGF inf usion (Fig. 5b). Again, there was no immunotoxin-induced effect on reactivity $\left(F_{(2,38)}=1.66\right)$; however, treatment with NGF resulted in a highly increased $\operatorname{ASR}\left(F_{(1,38)}=34.93 ; p<0.0005\right.$; Fig. $\left.5 b\right)$. Seven of the 56 trials were null trials during which displacement was recorded in the absence of an acoustic stimulus. In contrast to the ASR, no group differences were found for the seven null trials $\left(F_{(5,38)}=0.76\right)$. All groups showed much greater responses to the acoustic stimuli in comparison with the null trial responses, in which means ranged from 34 to 46 units, indicating that sense of hearing was intact.

\section{NGF and 192Sap do not change acoustic perception for acoustic stimuli}

To test for degree of perception for acoustic stimuli, ABRs were measured in a representative subset of animals ( $n=2$ per group) using a click stimulus. The threshold was, for all animals, between 79.5 and $89.5 \mathrm{~dB}\left(F_{(5,6)}=0.89\right)$. This finding confirms that the perception of acoustic stimuli was similar among groups. In addition, acoustic perception was affected by neither 192Sap $\left(F_{(2,9)}\right.$ $=0.63)$ nor $\operatorname{NGF}\left(F_{(1,10)}=0.73\right)$.

\section{NGF improves spatial procedural learning during acquisition but does not affect retention, spatial memory, and swimming speed}

On the first day, animals were taught to escape to the marked but submerged platform in the water maze. The initial, visible portion of the task measures the ability of the animals to swim and to acquire the procedure by using intramaze cues. The following day, the same protocol was followed with the platform at the same location but unmarked and therefore hidden from the rats' view. This latter, hidden portion of the water maze testing tests spatial orientation and memory by requiring the use of extramaze cues.

Each test segment consisted of three consecutive two-trial blocks of $90 \mathrm{sec}$ maximum duration each day. Performance of all groups improved significantly with time (visible, $F_{(2,76)}=47.32$; $p<0.0001$; hidden, $\left.F_{(2,76)}=7.77 ; p<0.0001\right)$, and all groups learned at a similar rate (group-by-block interaction: visible, $F_{(10,76)}=0.64$; hidden, $F_{(0,76)}=0.89$; Fig. 6). These results demonstrate that all groups had intact vision and were motivated to learn both the procedure and the spatial location of the hidden platform. Overall repeated measures ANOVA across both the visible and hidden portions of the water maze testing indicated a significant group effect $\left(F_{(5,38)}=2.5 ; p<0.05\right)$. The latency to escape to the platform was longer for rats given the high dose of immunotoxin and not treated with NGF (high-192Sap/CytC vs $\mathrm{PBS} / \mathrm{CytC}, p<0.05$ ), confirming previous results (Waite et al., 1995). In particular, a large divergence of latencies occurred in the middle of testing by switching from the visible to the hidden portion of the water maze testing (Fig. 6, block 4). The escape latency to locate the platform was, as expected, much longer during the first block of the hidden segment compared with the final block of the visible segment $\left(F_{(1,38)}=23.28 ; p<0.0005\right)$. No group-by-block interaction was evident $\left(F_{(5,38)}=0.99\right)$, indicating all groups experienced similar difficulties in finding the submerged platform. However, there was a significant effect among groups $\left(F_{(5,38)}=4.0 ; p<0.006\right)$. The latency of the high-192Sap/ $\mathrm{CytC}$ group to locate the platform was significantly longer compared with the PBS/CytC group $(p<0.005)$. In addition, the high-192Sap/NGF group needed significantly less time to find the platform compared with the high-192Sap/CytC group $(p<0.05)$. These results indicate that high-dose immunotoxic lesioned animals show slower procedural learning exacerbated by the added challenge of locating the hidden platform. However, treatment with NGF alleviated this deficit. Interestingly, NGF did not affect performance of PBS-injected animals during acquisition of either the visible or the hidden portion.

The mean latencies of the retention block (two trials each of 90 
Table 2. Assessment of open field activity and Morris water maze performance

\begin{tabular}{|c|c|c|c|c|c|}
\hline \multirow[b]{2}{*}{ Group } & \multicolumn{2}{|l|}{ Open field } & \multicolumn{3}{|c|}{ Morris water maze } \\
\hline & $\begin{array}{l}\text { Crossing } \\
(1 \mathrm{~min})\end{array}$ & $\begin{array}{l}\text { Crossing } \\
(5 \text { min })\end{array}$ & $\begin{array}{l}\text { Retention } \\
(\mathrm{sec})\end{array}$ & $\begin{array}{l}\text { Spatial probe } \\
(\%)\end{array}$ & $\begin{array}{l}\text { Speed } \\
(\mathrm{cm} / \mathrm{sec})\end{array}$ \\
\hline $\mathrm{PBS} / \mathrm{CytC}(n=7)$ & $12.9 \pm 1.3$ & $23.6 \pm 2.8$ & $62.8 \pm 16.4$ & $6.5 \pm 1.1$ & $36.5 \pm 1.3$ \\
\hline PBS/NGF $(n=8)$ & $12.9 \pm 2.5$ & $28.8 \pm 6.8$ & $45.8 \pm 12.8$ & $6.1 \pm 0.5$ & $37.5 \pm 1.1$ \\
\hline Low-192IgG/CytC $(n=8)$ & $10.4 \pm 1.4$ & $26.4 \pm 3.7$ & $41.5 \pm 12.0$ & $7.4 \pm 1.2$ & $38.8 \pm 0.5$ \\
\hline Low-192IgG/NGF $(n=9)$ & $13.0 \pm 1.7$ & $34.6 \pm 4.6$ & $58.2 \pm 14.8$ & $6.3 \pm 1.0$ & $36.6 \pm 1.0$ \\
\hline High-192IgG/CytC $(n=6)$ & $12.3 \pm 1.6$ & $37.2 \pm 3.0$ & $74.3 \pm 26.3$ & $5.3 \pm 1.1$ & $42.0 \pm 0.8^{*}$ \\
\hline High-192IgG/NGF $(n=6)$ & $9.8 \pm 3.1$ & $25.7 \pm 9.8$ & $75.0 \pm 12.1$ & $4.8 \pm 1.1$ & $39.2 \pm 1.4$ \\
\hline
\end{tabular}

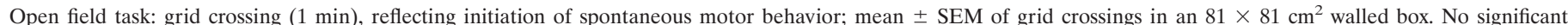

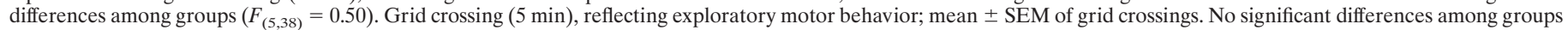

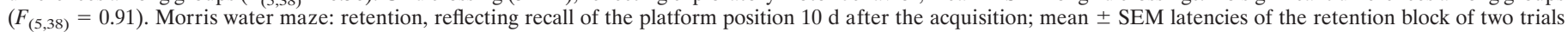

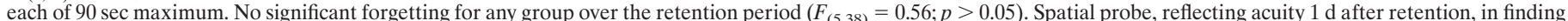

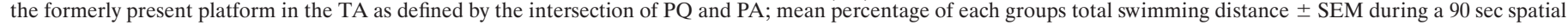

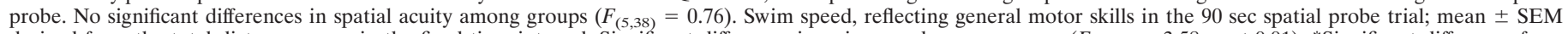

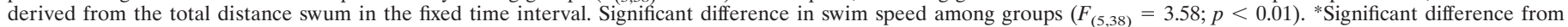
PBS/CytC, $p<0.05$.

sec maximum), obtained $10 \mathrm{~d}$ after the acquisition, showed a pattern similar to the last block of the acquisition (hidden portion of water maze testing). There was no significant forgetting for any group over the retention period $\left(F_{(5,38)}=0.56\right)$ and no significant interaction, indicating that all groups remembered at a similar level $\left(F_{(5,38)}=0.97\right.$; Table 2$)$.

One day after the retention block, spatial memory was measured in a $90 \mathrm{sec}$ spatial probe trial in which the platform was not present. Spatial accuracy was determined as percentage of the total distance swum in the PQ and the TA as defined by the intersection of the PQ and PA. Both parameters were not significantly different in the overall analysis of the experimental groups $\left(\mathrm{PQ}, F_{(5,38)}=0.73 ;\right.$ TA, $F_{(5,38)}=0.76$, Table 2$)$. These results demonstrate that all groups, after once learning the spatial location of the hidden platform, had a similar accuracy to relocate its position using extramaze cues.

The swimming speed was determined in the fixed $90 \mathrm{sec}$ spatial probe trial. There was a significant difference in swim speed among groups $\left(F_{(5,38)}=3.58 ; p<0.01\right)$. Table 2 shows that the high-192Sap/CytC group swam $12 \%$ faster than the PBS/CytC group and $8 \%$ faster than low-192sap/CytC group, respectively. However, corresponding CytC- and NGF-treated groups given the same degree of lesioning were not different from each other. Two-way ANOVA for each of the variables, lesion (PBS, low192Sap, and high-192Sap) and treatment (CytC and NGF), indicated that the hyperkinetic response to the swimming situation was attributable to the immunotoxic lesioning $\left(F_{(2,38)}=5.99 ; p<\right.$ $0.01)$ not to the treatment with $\operatorname{NGF}\left(F_{(1,38)}=2.32\right)$. This was in particular evident for the high-192Sap/CytC group, which swam significantly faster than PBS/CytC and low-192Sap/CytC $(p<$ 0.05). Despite the faster swimming speed of high-192Sap, the latency to escape to the platform during acquisition was longer in these animals.

\section{NGF decreased IAR independent of the preexisting cholinergic lesion}

Single-trial, step-through IA of a foot shock was tested. All groups entered the dark compartment shortly after the guillotine door was removed during the training trial. There was no significant difference among groups for the latency of initial entry on the training day $\left(H_{(5)}=1.36\right.$; Fig. $\left.7 a\right)$. However, the KruskalWallis test for the IAR trial revealed a significant group effect $\left(H_{(5)}=15.37 ; p=0.009\right)$. NGF-treated animals in general tended to enter the dark compartment much faster than the corresponding CytC-treated animals in the retention trial (Fig. 7b). There was a significant difference between the low-192Sap/CytC and low-192Sap/NGF ( $p<0.05$, Mann-Whitney $U$ test) and the high-192Sap/CytC and high-192Sap/NGF $(p<0.05$, MannWhitney $U$ test).

\section{DISCUSSION}

Numerous studies have established that NGF ameliorates deficits associated with cholinergic deafferentation (Hefti, 1986; Williams et al., 1986; Winkler and Thal, 1995). However, previous lesions destroyed noncholinergic neurons and confounded the interpretation of the restorative potential of NGF for CBF neurons (Dunnett et al., 1991; Winkler and Thal, 1995). 192Sap provides the means to test the effect of NGF in a model of cholinergic hypofunctioning because of its specificity for p75NGFrexpressing CBF neurons (Wiley, 1992). By using graded lesions, one can determine the degree of remaining cholinergic functioning necessary for NGF to alleviate the CBF damage. However, some of the functional deficits must be interpreted with consideration of the Purkinje cell loss after ICV administration of 192Sap (Waite et al., 1995).

\section{NGF has a limited capacity to restore ChAT activity}

Two doses of 192Sap (1 or $2.7 \mu \mathrm{g}$ ) induced 50-80\% ChAT depletion in $\mathrm{CBF}$ projections without affecting monoamine neurotransmitter levels. NGF increased ChAT activity most in PBS, intermediate in low-, and smallest in high-192Sap animals. Overall ChAT activity was increased in PBS animals by $42 \%$, with NGF bolstering ChAT activity by $57 \%$ in the frontal cortex and $26 \%$ in the hippocampus. In low-192Sap animals, ChAT depletion was fully restored in the frontal cortex only, followed by the parietal cortex and olfactory bulb. In high-192Sap animals, NGF failed to significantly elevate ChAT activity despite histological evidence of hypertrophic changes. This demonstrates that NGF has a limited capacity to restore ChAT activity and that the restorative potential of NGF depends on the amount of remaining cholinergic innervation. Additionally, highly depleted CBF projections such as the hippocampus showed smaller NGFinduced increases in ChAT activity than the less deafferented frontal cortex. This suggests that NGF is capable of significantly increasing ChAT activity only if substantial residual ChAT activity is preserved, probably requiring $\sim 50 \%$ of residual ChAT 
a.

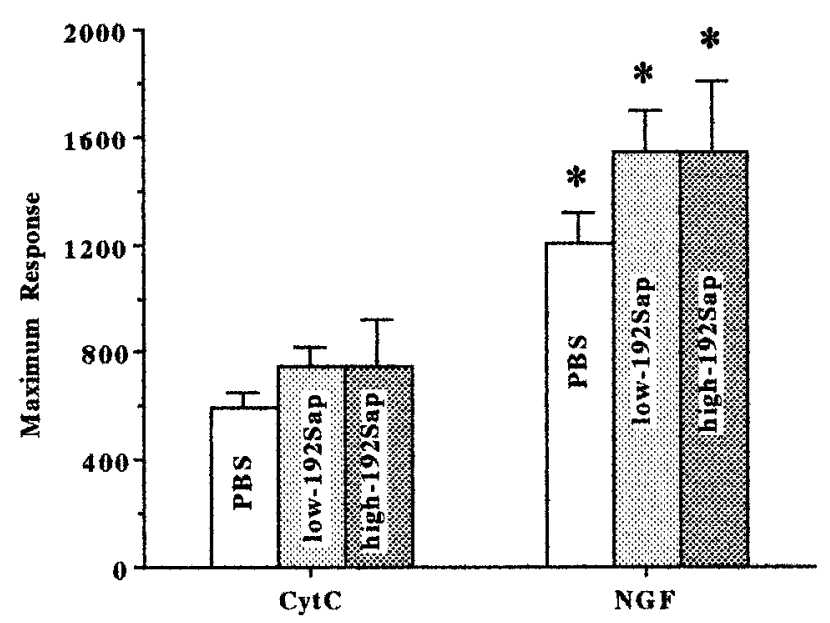

b.

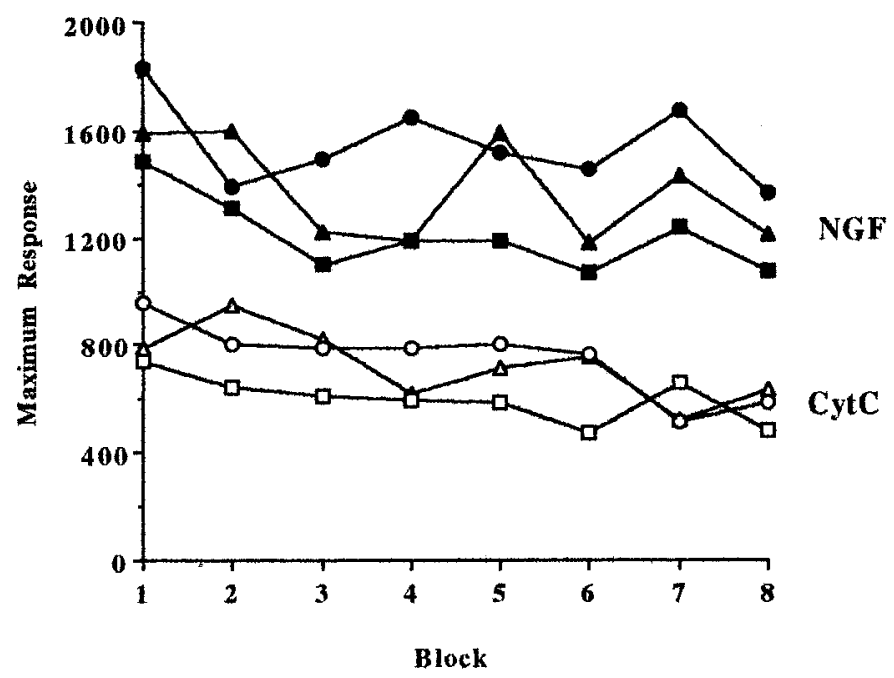

Figure 5. $a$, Acoustic startle-NGF induces motor hyper-reactivity. NGF treatment resulted in an increased motor reactivity recorded as maximal response to acoustic stimuli (in arbitrary units) averaged across blocks. Note that NGF-induced hyper-reactivity was independent of the preexisting degree of cholinergic deafferentiation. Mean \pm SEM displacements are given. *Significant difference from the corresponding CytC-group; PBS, low-192Sap, and high-192Sap, $p<0.005$. $b$, Acoustic startle - habituation to repeated acoustic stimuli is unaffected by NGF and cholinergic deafferentation. Acoustic startle testing consisted of eight blocks of six consecutive trials applying a $115 \mathrm{~dB}$ acoustic stimulus. Startle response to the acoustic stimulus is measured by a piezoelectric accelerometer and recorded in arbitrary units. Each point represents the average maximum response of each group. There are significant effects of group $\left(F_{(5,38)}=8.1 ; p<0.0001\right)$ and block $\left(F_{(7,266)}=3.5 ; p<0.001\right)$ but no group-by-block interaction $\left(F_{(35,266)}=0.7\right)$, indicating that the animals habituated similarly to the repeated acoustic stimuli despite group differences in response. In particular, NGF induced a significantly higher maximal motor response to the consecutive acoustic stimuli compared with the CytC-treated animals. Note that the habituation and the motor reactivity are not affected by the different degrees of cholinergic deafferentation. Open squares, PBS/CytC; closed squares, PBS/NGF; open circles, low-192Sap/CytC; closed circles, low-192Sap/NGF; open triangles, high192Sap/CytC; closed triangles, high-192Sap/NGF.

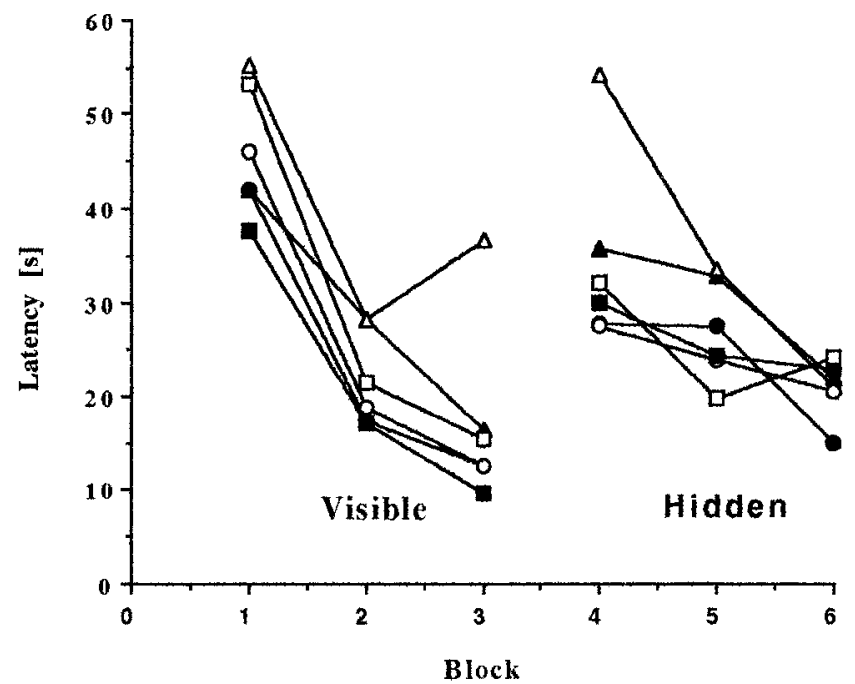

Figure 6. Water maze-NGF improves spatial orientation during acquisition. Animals were first taught to escape to a marked, submerged platform in the water maze (visible portion of the acquisition). On the following day, the platform was in the same location but unmarked and therefore hidden from the rats' view (hidden portion of the acquisition). Three consecutive two-trial blocks of $90 \mathrm{sec}$ maximum duration were run each day. Overall repeated measures ANOVA indicated a significant group effect $\left(F_{(5,38)}=2.5 ; p<0.05\right)$. The latency to escape to the platform was overall significantly longer for the high-192Sap/CytC, whereas NGF mitigated this deficit $(p<0.05)$. Latencies diverged by removing the visible cues from the platform. The comparison of the final block of the visible portion (Block 3) to the first block of the hidden portion (Block 4) revealed a significant group effect $\left(F_{(5,38)}=4.0 ; p<0.006\right)$. Only the high-192Sap/CytC group required significantly more time to locate the platform compared with the PBS/CytC $(p<0.005)$ and the corresponding high-192Sap/NGF groups $(p<0.05)$. Each point represents the average of the latencies over the two trials within each block. Open squares, PBS/CytC; closed squares, PBS/NGF; open circles, low-192Sap/ CytC; closed circles, low-192Sap/NGF; open triangles, high-192Sap/CytC; closed triangles, high-192Sap/NGF.

activity. This finding may have major therapeutic implications, because effective NGF treatment would have to be initiated, when a cholinergic deficit is still partial or even before clinical signs are evident.

The degree of restored ChAT activity by NGF after immunotoxic lesioning is higher than after excitotoxic NBM lesions (Winkler and Thal, 1995). For example, lesions induced by ibotenic and quisqalic acid, which resulted in 32 and $39 \%$ depletion in frontal cortex ChAT activity, were only partly restored by NGF; however a $32 \%$ depletion by 192 Sap was fully restored using the same NGF treatment. Lower NGF responsiveness after excitoxic lesioning may be related to the fact that noncholinergic neuronal loss occurs after excitotoxic injections, which may restrict the potential of NGF to stimulate residual cholinergic neurons.

\section{NGF induces CBF hypertrophy and Schwann cell hyperplasia}

In contrast to the limited restoration of ChAT activity, the size and arborization of the residual CBF neurons were increased by NGF independent of the extent of neuronal loss. These changes in high-192Sap animals may be the correlate for their improved procedural learning. This finding is in agreement with previous studies showing that structural alterations of CBF neurons are more closely related to the performance of animals in tests of spatial memory than changes in the terminal fields (Fischer et al., 1987). Schwann cell hyperplasia occurred in all NGF-treated 

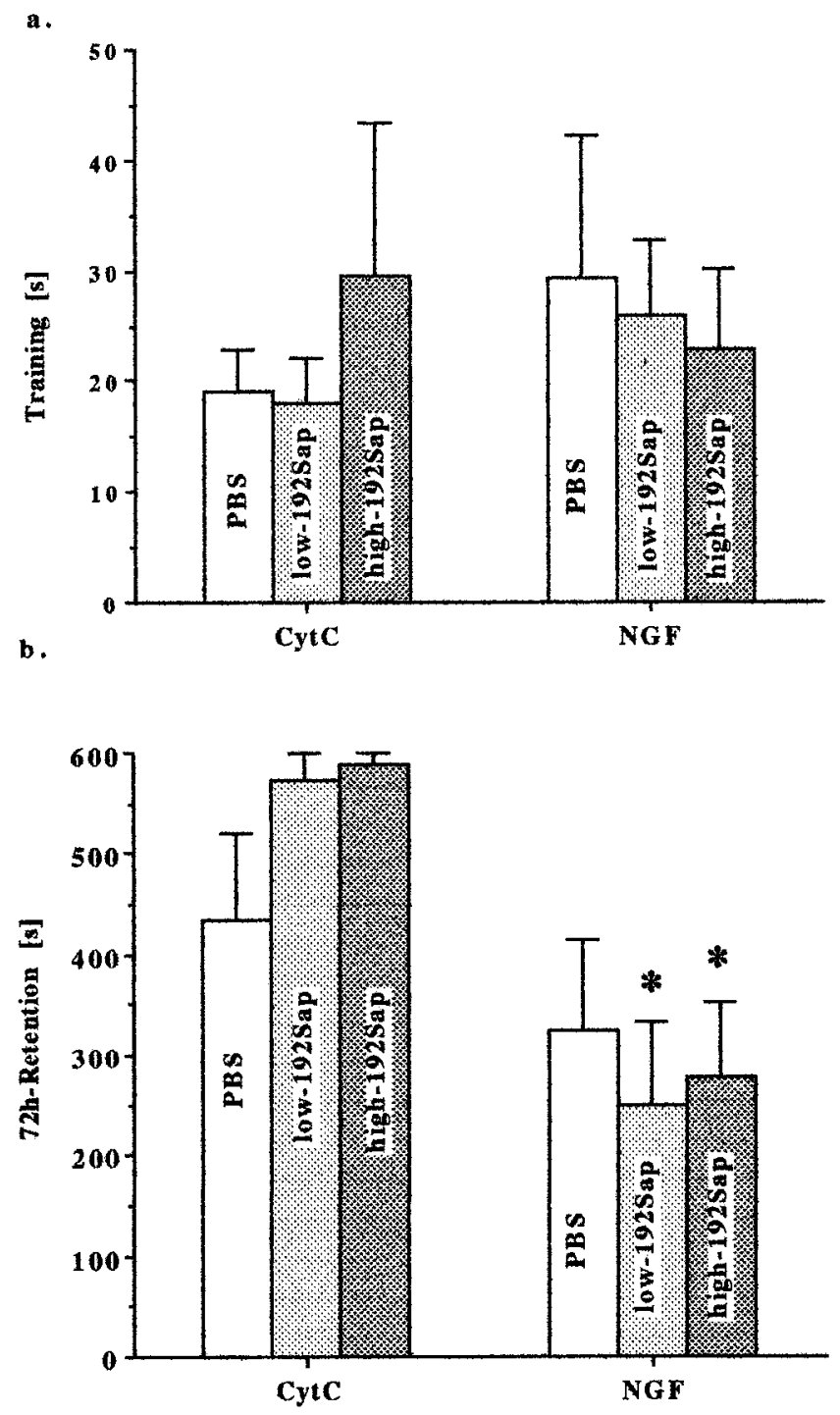

Figure 7. a, IA-spontaneous crossing is unaffected by NGF and cholinergic deafferentation. IA was tested using a two-compartment box. First, each animal was placed in a lighted compartment. A guillotine door to the dark compartment was raised, and a timer began to record stepthrough latency. Entry was considered complete when all four paws had entered the dark chamber. Single step-through training trial reflects spontaneous crossing from the bright to the dark compartments. Latencies to enter the dark compartment are expressed as means \pm SEM. No significant differences were observed among groups $\left(H_{(5)}=1.36\right)$. Afterward, the door was closed, and a $0.65 \mathrm{~mA}$ AC scrambled current was applied. $b$, IA-NGF impairs $72 \mathrm{hr}$ retention using a single, step-through retention trial. Seventy-two hours after the training trial, single trial, step-through latency as described above was assessed with a maximum time of $600 \mathrm{sec}$. NGF-treated animals entered the dark compartment significantly earlier compared with the corresponding CytC group. Data are expressed as means \pm SEM. *Significant difference from the corresponding CytC-group, $p<0.05$, Mann-Whitney $U$ test.

animals. This neuroproliferative effect is dose-dependent but transient in nature (Day-Lollini et al., 1997; Winkler et al., 1997). The functional consequences of these changes remain unknown, and correlations between them and behaviors observed during ASR and IA cannot be imputed.

\section{NGF improves water maze performance}

In agreement with previous studies of animals with cholinergic deficits, NGF partially improved the immunotoxin-induced spa- tial memory deficit (Fischer et al., 1987; Markowska et al., 1994; Winkler and Thal, 1995). The water maze paradigm was designed to first test the rats' ability to acquire the procedure and locate the platform. Removing intramaze cues forced the rat to find the platform at the same location the next day using extramaze cues. This challenge to procedural learning and recent memory required a sophisticated spatial orientation and revealed a deficit in highly lesioned animals, which was partially alleviated by NGF.

\section{NGF induces adverse nonmnemonic behaviors}

NGF produced a surprising number of unanticipated behavioral changes. These behaviors were independent of the preexisting cholinergic deficit and consisted of differences in body weight gain and the processing of acoustic, visual, and nociceptive stimuli.

NGF-induced hypophagia has been previously reported (Williams, 1991; Winkler et al., 1998) and may seriously limit longterm intracerebroventricular administration of NGF in AD patients (Jönhagen et al., 1998). One potential target of NGF may be hypothalamic circuits resulting in decreased levels of cholecystokinin, a peptide that is involved in maintaining food intake (Lapchak and Araujo, 1994).

NGF induced hyperreactivity during the ASR without affecting habituation to the acoustic stimuli. The ASR is mediated by a neural circuit including the cochlear nuclei, the pontine reticular formation, and spinal motorneurons (Yeomans and Frankland, 1996). To control for acoustic-related enhancement of the ASR, the ABR, which assesses the acoustic afferents from the vestibulocochlear nerve to the thalamus, was measured. Our data indicated that this component of the ASR was not differently modulated by NGF. However, ASRs may be modulated by stimulating nonacoustic pathways. In particular, stimulation of descending pathways passing from the amygdala to the hindbrain can lead to ASR and are important in "fear" potentiation of ASR (Rosen and Davis, 1990; Yeomans and Pollard, 1993). In this regard, it is noteworthy that the cholinergic NBM-amygdala projecting neurons, which do not express p75NGFr, are preserved after immunotoxin lesions (Heckers et al., 1994). Furthermore, NGF facilitates cholinergic neurotransmission between these nuclei (Moises et al., 1995). Thus, one potential explanation of the NGF-induced hyperreactivity may be related to the stimulation of the preserved NBM-amydaloid projection facilitating ASR via amygdaloid outputs to the pontine reticular formation. In agreement with this hypothesis, Rosen and Davis (1988a,b) and Koch and Ebert (1993) reported that electrical or NMDA stimulation of this pathway enhances the ASR. In addition, a recent study showed that NGF modulates information processing in the auditory thalamus by changing firing properties of the thalamic reticular nucleus, which plays a critical role in gating cortical processing of acoustic, visual, or somatosensory inputs (Villa et al., 1996).

NGF treatment decreased IAR independent of the preexisting cholinergic deficit. This finding was not anticipated for several reasons. Single-trial, step-through IAR has been broadly used as a test for recall (Santucci et al., 1989; Torres et al., 1994). The conclusion that the $\mathrm{CBF}$ modulates recall was initially drawn from behavioral studies using compounds modulating cholinergic neurotransmission. Using cholinesterase inhibitors in lesioned animals (Santucci et al., 1989; Aaltonen et al., 1991), performance of IAR was improved, whereas cholinergic muscarinic antagonists impaired performance (Lo Conte et al., 1982). More controversial are the findings based on CBF lesions, which report both the lack (Connor et al., 1991; Wenk et al., 1994) and presence (Dunnett et al., 1987; Torres et al., 1994) of a retention deficit 
after excitotoxic or immunotoxic lesioning. The degree of cholinergic cell loss, variation in inhibitory avoidance paradigms, and/or the use of different toxins at various dosages have contributed to this ambiguity. The NGF-related behavioral effect cannot be attributed to a general hyperkinesia, because general motor behavior was not affected. Additionally, this effect is not related to a general deficit in acquisition, because the retention latencies were longer compared with the training trial. An alternative explanation for this NGF-related behavior is that the bright compartment may induce a fear-related behavior via preserved NBM cholinergic outputs depolarizing amygdaloid neurons (Moises et al., 1995). Thus, the NBM-amygdala output may be unopposed and lead the animals to step into the dark compartment. Another possibility is that 192Sap lesions may lower the sensitivity of the rats to the shock, and NGF may "normalize" this sensitivity.

\section{Clinical perspective}

Considering the diverse NGF-related outcomes, it is apparent that NGF acts on various neuronal populations, thereby modulating different behaviors. These effects may be independent of the CBF status, which appears to predominantly involve mnemonic processing. This raises the possibility of additional adverse effects of NGF. Selectively focusing only on cholinergically mediated outcomes is not sufficient to address the results that would be obtained with the use of NGF in the clinic. Although NGF is a potent trophic factor for restoring CBF functions, intracerebroventricular administration results in detrimental changes, which must be considered before implementing this therapy for patients. The first clinical report of AD patients after intracerebroventricular treatment of NGF supports this view, because all patients experienced severe back pain, weight loss, and anxiety but no cognitive improvement (Jönhagen et al., 1998). These adverse effects were transient but severe enough to lead to a termination of the NGF infusion. Alternative strategies such as in vivo or ex vivo gene therapy approaches to deliver NGF locally to the compromised $\mathrm{CBF}$ need to be explored further to circumvent these effects associated with the intracerebroventricular mode of administration.

\section{REFERENCES}

Aaltonen M, Riekkinen P, Sirviö J, Riekkinen Jr P (1991) Effects of THA on passive avoidance and spatial perfrmance in quisqualic acid nucleus basalis-lesioned rats. Pharmacol Biochem Behav 39:563-567.

Bartus RT, Dean III RL, Beer B, Lippa AS (1982) The cholinergic hypothesis of geriatric memory dysfunction. Science 217:408-417.

Berger-Sweeney J, Heckers S, Mesulam MM, Wiley RG, Lappi D, Sharma M (1994) Differential effects on spatial navigation of immunotoxin-induced cholinergic lesions of the medial septal area and nucleus basalis magnocellularis. J Neurosci 14:4507-4519.

Collerton D (1986) Cholinergic function and intellectual decline in Alzheimer's disease. Neuroscience 19:1-28.

Connor DJ, Langlais PJ, Thal LJ (1991) Behavioral impairments after lesions of the nucleus basalis by ibotenic acid and quisqualic acid. Brain Res 555:84-90.

Coyle JT, Price DL, DeLong MR (1983) Alzheimer's disease: a disorder of central cholinergic innervation. Science 219:1184-1190.

Cummings JL, Kaufer D (1996) Neuropsychiatric aspects of Alzheimer's disease: The cholinergic hypothesis revisited. Neurology 47:876-883.

Davis KL, Mohs RC, Marin D, Purohit DP, Perl DP, Lantz M, Austin G, Haroutunian V (1999) Cholinergic markers in elderly patients with early signs of Alzheimer disease. JAMA 281:1401-1434.

Day-Lollini PA, Stewart GR, Taylor MJ, Johnson RM, Chellman GJ (1997) Hyperplastic changes within the leptomeninges of the rat and monkey in response to chronic intracerebroventricular infusion of nerve growth factor. Exp Neurol 145:24-37.
Dekker AJ, Gage FH, Thal LJ (1992) Delayed treatment with nerve growth factor improves acquisition of a spatial task of the nucleus basalis magnocellularis: evaluation of the involvement of different neurotransmitter systems. Neuroscience 48:111-119.

DeKosky ST, Harbourgh RE, Schmitt FA, Bakay RAE, Chui HC, Knopman DS, Reeder TM, Shetter AG, Senter HJ, Markesbery WR (1992) Cortical biopsy in Alzheimer's disease: diagnostic accuracy and neurochemical, neuropathological, and cognitive correlations. Ann Neurol 32:625-632.

Dixon WJ, Massey FJ (1983) Introduction to statistical analysis. New York: McGraw-Hill.

Dunnett SB, Whishaw IQ, Jones GH, Bumch ST (1987) Behavioral, biochemical and histochemical effects of different neurotoxic amino acids injected into nucleus basalis magnocellularis of rats. Neuroscience 20:653-669.

Dunnett SB, Everitt BJ, Robbins TW (1991) The basal forebrain-cortical cholinergic system: interpreting the functional consequences of excitotoxic lesions. Trends Neurosci 14:494-501.

Emmett CJ, Aswani SP, Stewart GR, Fairchild D, Johnson RM (1995) Dose response comparison of recombinant human basic fibroblast growth factor in the fimbria fornix model of acute cholinergic degeneration. Brain Res 673:199-207.

Emre M, Heckers S, Mash DC, Geula C, Mesulam MM (1993) Cholinergic innervation of the amydaloid complex in the human brain and its alterations in old age and Alzheimer's disease. J Comp Neurol 336:117-134.

Fibiger HC (1991) Cholinergic mechanisms in learning, memory and dementia: a review of recent evidence. Trends Neurosci 14:220-223.

Fischer W, Wictorin K, Björklund A, Williams LR, Varon S, Gage FH (1987) Amelioration of cholinergic neuron atrophy and spatial memory impairment in aged rats by nerve growth factor. Nature 329:65-68.

Fonnum F (1969) Radiochemical microassays for the determination of choline acetyltransferase and acetylcholinesterase activities. J Biochem 115:465-479.

Fusco M, Oderfeld-Nowak B, Vantini G, Schiavo N, Gradkowska M, Zaremba M, Leon A (1989) Nerve growth factor affects uninjured, adult rat septohippocampal cholinergic neurons. Neuroscience 33:47-52.

Francis PT, Palmer AM, Sims NR, Bowen DM, Davison AN, Esiri MM, Neary D, Snowden JS, Wilcock GK (1985) Neurochemical studies in early-onset Alzheimer's disease. N Engl J Med 313:7-11.

Heckers S, Mesulam MM (1994) Two types of cholinergic projections to the rat amygdala. Neuroscience 60:383-397.

Heckers S, Ohtake T, Wiley FG, Lappi DA, Geula C, Mesulam MM (1994) Complete and selective cholinergic denervation of rat neocortex and hippocampus but not amygdala by an immunotoxin against the p75 NGF receptor. J Neurosci 14:1271-1289.

Hefti F (1986) Nerve growth factor promotes survival of septal cholinergic neurons after fimbrial transections. J Neurosci 6:2155-2162.

Hefti F (1994) Neurotrophic factor therapy for nervous system degenerative diseases. J Neurobiol 25:1418-1435.

Henderson JT, Senuik NA, Richardson PM, Gauldie J, Roder JC (1994) Systemic administration of ciliary neurotrophic factor induces cachexia in rodents. J Clin Invest 93:2632-2638.

Jönhagen ME, Nordberg A, Amberla K, Bäckmann L, Ebendal T, Meyerson B, Olson L, Seiger A, Shigeta M, Theodorsson E, Viitanen M, Winblad B, Wahlund LO (1998) Intra-cerebroventricular infusion of nerve growth factor in three patients with Alzheimer's disease. Dement Geriatr Cogn Disord 9:246-257.

Keithley EM, Woolf NK, Harris JP (1989) Development of morphological and physiological changes in the cochlea induced by cytomegalovirus. Laryngoscope 99:409-414.

Kesner RP (1988) Reevaluation of the contribution of the basal forebrain cholinergic system to memory. Neurobiol Aging 9:609-616.

Koch M, Ebert U (1993) Enhancement of the acoustic startle response by stimulation of an excitatory pathway from the central amygdala/ basal nucleus of Meynert to the pontine reticular formation. Exp Brain Res 93:231-241.

Lapchak PA, Araujo DM (1994) NGF suppression of weight gain in adult female rats correlates with decreased hypothalamic cholecystokinin levels. Brain Res 655:12-16.

Lapchak PA, Hefti F (1991) Effect of recombinant human nerve growth factor on presynaptic cholinergic function in rat hippocampal slices following partial septohippocampal lesions: measures of $\left[{ }^{3} \mathrm{H}\right]$ acetylcho- 
line synthesis, $\left[{ }^{3} \mathrm{H}\right]$ acetylcholine release and choline acetyltransferase activity. Neuroscience 42:639-649.

Lapchak PA, Hefti F (1992) BDNF and NGF treatment in lesioned rats: effects on cholinergic function and weight gain. NeuroReport 3:405-408.

Lehericy S, Hirsch EC, Cervera-Pierot P, Hersh LB, Bakchine S, Piette F, Duyckaerts C, Hauw JJ, Javoy-Agid F, Agid Y (1993) Heterogeneity and selectivity of the degeneration of cholinergic neurons in the basal forebrain of patients with Alzheimer's disease. J Comp Neurol 330:15-31.

Lo Conte G, Bartolini L, Casamenti F, Marconcini-Pepeu I, Pepeu G (1982) Lesions of cholinergic forebrain nuclei: changes in avoidance behavior and scopolamine actions. Pharmacol Biochem Behav 17:933-937.

Lowry OH, Rosebrough NJ, Farr AL, Randall RJ (1951) Protein measurement with the phenol reagent. J Biol Chem 193:265-275.

Markowska AL, Koliatsos VE, Breckler SJ, Price DL, Olton DS (1994) Human nerve growth factor improves spatial memory in aged but not in young rats. J Neurosci 14:4815-4824.

Moises HC, Womble MD, Washburn MS, Williams LR (1995) Nerve growth factor facilitates cholinergic neurotransmission between nucleus basalis and the amygdala in rat: an electrophysiological analysis. J Neurosci 15:8131-8142.

Paxinos G, Watson C (1986) The rat brain in stereotaxic coordinates. New York: Academic.

Rosen JB, Davis M (1988a) Enhancement of acoustic startle by electrical stimulation of the amygdala. Behav Neurosci 102:195-202.

Rosen JB, Davis M (1988b) Temporal characteristics of enhancement of startle by stimulation of the amydala. Physiol Behav 44:117-123.

Rosen JB, Davis M (1990) Enhancement of electrically elicited startle by amygdaloid stimulation. Physiol Behav 48:343-349.

Rylett RJ, Goddard S, Schmidt BM, Williams LR (1993) Acetylcholine synthesis and release following continuous intracerebral administration of NGF in adult and aged Fischer-344 rats. J Neurosci 13:3956-3963.

Santucci AC, Kanof PD, Haroutunian V (1989) Effect of physostigmine on memory consolidation and retrieval processes in intact and nucleus basalis-lesioned rats. Psychopharmacology 99:70-74.

Sarter M, Bruno JP (1997) Cognitive functions of cortical acetylcholine: toward a unifying hypothesis. Brain Res Rev 23:28-46.

Stirpe F, Barbieri L, Battelli MG, Soria M (1992) Ribosome-inactivating proteins from plants-present status and future prospects. Biotechnology 10:405-412.

Torres EM, Perry TA, Blokland A, Wilkinson LS, Wiley RG, Lappi DA, Dunnett SB (1994) Behavioural, histochemical and biochemical consequences of selective immunolesions in discrete regions of the basal forebrain cholinergic system. Neuroscience 63:95-122.
Villa AEP, Bajo Lorenzana VM, Vantini G (1996) Nerve growth factor modulates information processing in the auditory thalamus. Brain Res Bull 39:139-147.

Waite JJ, Wardlow ML, Chen AD, Lappi DA, Wiley RG, Thal LJ (1994) Time course of cholinergic and monoaminergic changes in rat brain after immunolesioning with 192 IgG-saporin. Neurosci Lett 169:154-158.

Waite JJ, Chen AD, Wardlow ML, Wiley RG, Lappi DA, Thal LJ (1995) 192 immunoglobulin G-saporin produces graded behavioral and biochemical changes accompanying the loss of cholinergic neurons of the basal forebrain and cerebellar Purkinje cells. Neuroscience 65:463-476.

Walsh TJ, Kelly RM, Dougherty KD, Stackman RW, Wiley RG, Kutscher CL (1995) Behavioral and neurobiological alterations induced by the immunotoxin 192-IgG-saporin: cholinergic and non-cholinergic effects following i.c.v. injection. Brain Res 702:233-245.

Wenk GL, Stoehr JD, Quintana G, Mobley S, Wiley RG (1994) Behavioral, biochemical, histological, and electrophysiological effects of 192 IgG-saporin injections into the basal forebrain of rats. J Neurosci 14:5986-5995.

Wiley RG (1992) Neural lesioning with ribosome-inactivating proteins: suicide transport and immunolesioning. Trends Neurosci 15:285-290.

Wiley RG, Oeltmann TN, Lappi DA (1991) Immunolesioning: selective destruction of neurons using immunotoxin to NGF receptor. Brain Res 562:149-153.

Williams LR (1991) Hypophagia is induced by intracerebroventricular administration of nerve growth factor. Exp Neurol 113:31-37.

Williams LR, Varon S, Peterson GM, Wictorin K, Fischer W, Björklund A, Gage FH (1986) Continuous infusion of nerve growth factor prevents basal forebrain neuronal death after fimbria fornix transection. Proc Natl Acad Sci USA 83:9231-9235.

Winkler J, Thal LJ (1995) Effects of nerve growth factor treatment on rats with lesions of the nucleus basalis magnocellularis produced by ibotenic acid, quisqualic acid, and AMPA. Exp Neurol 136:234-250.

Winkler J, Ramirez GA, Kuhn HG, Peterson DA, Day-Lollini PA, Stewart GR, Tuszynski MH, Gage FH, Thal, LJ (1997) Reversible Schwann cell hyperplasia and sprouting of sensory and sympathetic neurites after intracerebroventricular administration of nerve growth factor. Ann Neurol 41:82-93.

Winkler J, Power AE, Ramirez GA, Thal LJ (1998) Short-term and complete reversal of NGF effects in rats with lesions of the nucleus basalis magnocellularis. Brain Res 788:1-12.

Yeomans JS, Frankland PW (1996) The acoustic startle reflex: neurons and connections. Brain Res Rev 21:301-314.

Yeomans JS, Pollard BA (1993) Amygdala efferents mediate electrically evoked startle-like responses and fear potentiation of acoustic startle. Behav Neurosci 107:596-610. 